\title{
Shifting Implementation Science Theory to Empower Primary Care Practices
}

William L. Miller, MD, $M A^{1}$

Ellen B. Rubinstein, $P b D, M A^{2}$

Jenna Howard, $P b D^{3}$

Benjamin F. Crabtree, $P b D, M A^{3}$

'Lehigh Valley Health Network/University of South Florida Morsani College of Medicine, Allentown, Pennsylvania

${ }^{2}$ Department of Sociology \& Anthropology, North Dakota State Universiry, Fargo, North Dakota

${ }^{3}$ Department of Family Medicine and Community Health, Rutgers Robert Wood Johnson Medical School, New Brunswick, New Jersey

Conflicts of interest: authors report none.

\section{CORRESPONDING AUTHOR}

Jenna Howard, $\mathrm{PhD}$

Department of Family Medicine and Community Health

Rutgers Robert Wood Johnson Medical School

112 Paterson Street

New Brunswick, NJ 08901

jenna.howard@rutgers.edu

\begin{abstract}
Observers of the past 10 to 15 years have witnessed the simultaneous growth of dramatic changes in the practice of primary care and the emergence of a new field of dissemination and implementation science (DEI). Most current implementation science research in primary care assumes practices are not meeting externally derived standards and need external support to meet these demands. After a decade of initiatives, many stakeholders now question the return on their investments. Overall improvements in quality metrics, utilization cost savings, and patient experience have been less than anticipated. While recently conducting a research project in primary care practices, we unexpectedly discovered 3 practices that profoundly shifted our thinking about the sources and directionality of practice change and the underlying assumptions of DEI. Inspired by these practices-along with systems thinking, complexity theory, action research, and the collaborative approaches of community-based participatory research-we propose a reimagining of DEI theory to empower practices. We shift the emphasis regarding the source and direction of change from outside-in to inside-out. Such a shift has the potential to open a new frontier in the science of dissemination and implementation and inform better health policy.
\end{abstract}

Ann Fam Med 2019;17:250-256. https://doi.org/10.1370/afm.2353.

\section{INTRODUCTION}

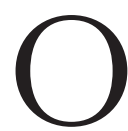
bservers of the past 10 to 15 years have witnessed dramatic changes in the practice of primary care and the simultaneous growth of a new field of dissemination and implementation science (D\&I). Often loosely organized around the construct of the patientcentered medical home $(\mathrm{PCMH}),{ }^{1}$ and aided by expanding knowledge in implementation science, primary care change initiatives have involved external stakeholders (eg, government agencies, foundations, health systems, private industry, insurance companies, and legislatures) investing resources into helping practices transform and implement the latest evidence with the aim of providing comprehensive, coordinated, continuous care, with improved quality and access for patients and lower cost to the health care system. ${ }^{1-3}$ These transformation efforts include adopting new technologies, redesigning workflows, redefining and/or adding workforce roles, encouraging multidisciplinary teams, ${ }^{4,5}$ and accelerating the dissemination and implementation of evidence-based care. ${ }^{6}$

Most current implementation science research in primary care assumes practices are not meeting externally derived standards and need external support to meet these expectations. ${ }^{7}$ Some efforts have focused on shifting payment incentives toward achieving quality metrics, ${ }^{8,9}$ while others focus on changing mental models, operations, and practice culture to accommodate new workforce roles and responsibilities, electronic health records (EHR), and team-based care. ${ }^{10-12}$ Several initiatives have worked toward improving practices' adaptive reserve and capacity for change. ${ }^{13-16}$

Many stakeholders now question the return on their investments. Overall improvements in quality metrics, utilization cost savings, and patient experience have been less than anticipated, ${ }_{1}^{17}$ costs of building 
PCMHs more than expected ${ }^{18,19}$ and challenges of EHR implementation and performance worse than planned. ${ }^{20}$ An alarming rise in primary care clinician burnout and staff turnover proved an unexpected surprise. ${ }^{21,22}$ This has occurred alongside an historic transition in which over one-half of the primary care clinician workforce is employed by large organizations creating a new source of external (to the practice) oversight and direction, ${ }^{23}$ complicating the ability for practices to create environments that optimize agency, mastery of craft, and purpose. ${ }^{24}$

Could the above upshots be related to an overall approach that disrespects and undervalues primary care as a coproducer of knowledge and inadvertently bullies practices into conforming to goals they did not choose? Recent comprehensive reviews of D\&I and its theories hint at an affirmative answer to this question. ${ }^{7,25,26}$ Nilsen identifies 3 aims of D\&I theory-process of translating research or evidence into practice; explaining what influences outcomes; and evaluating implementation - and 5 theoretical approaches related to these aims. ${ }^{7}$ Unstated, but assumed, is that the evidence, developed and tested in a context remote from settings of implementation, is appropriate to that setting. Rapport and colleagues urge D\&I investigators and users to return to foundational concepts but also, unstated, assume the universally applicable truth of the evidence. ${ }^{26}$ When reviewing the D\&I literature for impact of implementations on patient safety, Braithwaite and colleagues uncovered many unintended consequences of the interventions suggestively related to mismatches of evidence, implementation strategy, and practice context. ${ }^{25}$

Given these circumstances, we suggest current implementation science-based primary care interventions risk promoting scientific imperialism by predetermining the evidence, setting the research agenda, funding ideologically driven policies, and determining engagement and communication strategies. Inspired by systems thinking, complexity theory, and action research, ${ }_{1}^{27-29}$ as well as community-based participatory research's (CBPR) potential to build on social movement theories ${ }^{30}$ and "facilitate the decolonization of health research,"131 we propose a reimagining of D\&I theory to alter the power dynamic and re-empower practices by shifting the emphasis regarding the source and direction of change from outside-in to inside-out.

We recommend this reimagining for 3 main reasons. First, practices and health are best understood as complex adaptive systems with a dynamic interplay of forces acting upon one another. ${ }^{27,29,32-34}$ Everything in the system is related, which means that practice change or better health occurs among a multitude of actors and relationships and is not limited to the target intervention. ${ }^{28,35}$ This can result in unintended consequences and new issues to address as suggested by the Braithwaite, et al review regarding evidence implementation and patient safety. ${ }^{25}$ From a complexity science perspective, evidence based on linear, reductionist, controlled situations risks missing unintended adverse effects on other aspects of health as with patients suffering multimorbidity. Moving up to a practice level, interventions designed to improve performance on an identified metric such as blood pressure control, risks unanticipated and often unrecognized harm to other activities and outcomes of the practice.

Second, implementation science is, in fact, a science of sociocultural change and thus would benefit from a participatory epistemology. A participatory epistemology moves away from the attempted acquisition of objective facts and, instead, recognizes that all knowledge is filtered through social interactions and individual experiences. ${ }^{36,37}$ When D\&I research grounds its work on participatory epistemology, it asserts that practice and community engagement is where knowledge is discovered and implementation solutions developed. ${ }^{37,38}$ In practical terms, rather than telling practices what their reality is or should be, researchers could acknowledge practices' ability to identify the issues that are most important to them and to find their own solutions. ${ }^{31}$

Finally, D\&I would benefit from a theory that recognizes that knowledge production cannot be separated from everyday practice. Indeed, we should consider conditions for knowledge production to be "co-created" among researchers and practitioners. ${ }^{39,40}$ Using these key principles, along with 3 illustrative cases from a nationwide study on cancer survivorship care in PCMHs, ${ }^{41}$ we propose an inside-out theory of D\&I to empower practices.

\section{An Inside-Out Theory of DEI}

In our own work on practice observation, change initiatives and their evaluation, ${ }_{1}^{15,42-47}$ the practice change and development (PCD) model emerged and was modified as one way to conceptualize the factors and forces impacting practices' ability to change..$^{29,48}$ These factors include both elements of the practice (inside motivators and capability for development, or practice core and adaptive reserve) and elements of the external environment (outside motivators and options for development). The model, based on complex adaptive systems theory, was derived empirically through a mixed-methods comparative assessment of high- and low-performing primary care practices implementing an intervention to improve preventive services delivery. ${ }^{47}$ More recent evaluation of the PCMH National Demonstration Project refined the model. ${ }^{29}$ 
For this paper, we depict the PCD model (Figure 1) to highlight and describe not only the factors (Figure 1 slices) involved in practice change, but also the interactive forces (arrows connecting slices). While studies using the PCD and similar models have acknowledged the importance of the interaction of the internal practice with its external environment ${ }^{49}$ the forces have been portrayed as primarily unidirectional, acting from the outside-in, rather than reciprocally as the model depicts.

A modification of the PCD model (Figure 2) emphasizes our proposed reimagining. The practice (Figure 1, slices 1 and 2) now becomes both the source and the destination for practice changes. The role of practice facilitators (eg, from health extension service, health system owner, etc) shifts to helping practices better understand themselves and their communities of patients. They can then connect to potentially helpful outside motivators (Figure 1, slice 3 ) and development options including best available evidence (Figure 1 , slice 4) for helping them more optimally maintain agency, purpose, and mastery of craft. The new goals for D\&I become helping practices find ways to work with the external environment, address finance and payment, and match and codevelop evidence consistent with the craft and local complex particularities of primary care practice.

To our knowledge, there are no studies or models describing organizational action from the inside-out to mitigate external constraints and leverage hidden opportunities to enable their vision. A Dynamic Sustainability Framework (DSF) for implementation science, proposed in $2013,{ }^{50}$ points in this direction by recognizing the limited utility of early-stage testing of interventions in artificial conditions. It encourages practices to change the evidence and intervention to create a contextual fit for each practice's idiosyncratic environment. Building flexibility into implementation can improve intervention sustainability and lead to the cocreation of a learning health care system..$^{51}$ Our proposed reimagining of the PCD model further suggests that practices be sources for deciding what evidence and interventions are needed. The scope is no longer limited to generating evidence and associated quality measures; rather, the ability to practice the craft of primary care emerges as both a key component of quality and a critical element in developing evidence.

While recently conducting a research project in primary care practices, we unexpectedly discovered 3 practices that profoundly shifted our thinking about the sources and directionality of practice change. We present them here to illustrate our inside-out theory of D\&I.

\section{Three Practices From the Inside-Out}

The 3 practices were part of a national, mixedmethods comparative case study investigating care for cancer survivors in 14 primary care practices recognized for workforce innovation. We have discussed the study's iterative sampling, recruitment, and data collection strategies elsewhere. ${ }^{41}$ This study was approved by the Rutgers Institutional Review Board (IRB Protocol No: 2013003629). Within the context of the larger study, ${ }^{41}$ these 3 practices were unremarkable; they similarly lacked comprehensive cancer survivorship services. From the perspective of practice transformation, however, they proved singular. Unlike the other practices, which organized staffing and workflows to meet external pressures and targets, these pioneer practices established their own goals and then managed the external environment in order to reorganize internal operations. Change, implementation, and dissemination were sourced and driven internally. We examined these 3 practices' approaches to the external environment through their business models, ${ }^{52}$ using the frame-
Note: This figure represents a modified depiction of the Practice Change and Development (PCD) Model29,48 with contents of each slice specified. Adapted with permission from Cohen D, McDaniel RR Jr, Crabtree BF, et al. A practice change model for quality improvement in primary care practice. J Healthc Manag. 2004;49(3):155-168, discussion 169-170. 


\section{Figure 2. Shifting the implementation science emphasis to inside-out.}

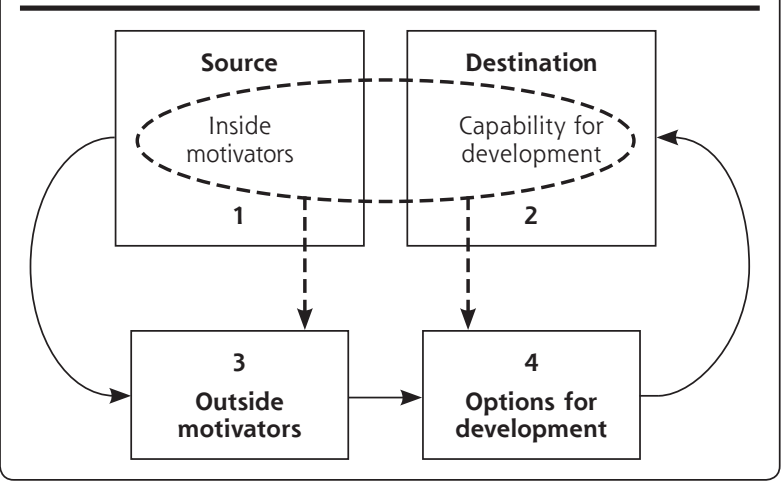

work for entrepreneurial business models by Morris, et $\mathrm{al}_{1}^{53}$ which identifies 6 components of a business model: offering/service, market, internal capability, competitive strategy, economics, and growth. We organized our results according to 5 components, leaving out competitive strategies because we could not access necessary proprietary information. As a form of member checking, ${ }^{54} 1$ representative from each practice reviewed our characterization of their model for accuracy, resulting in minor revisions.

These innovators began with the same premise: the current policy and economic landscape, especially the fee-for-documentation and pay-for-performance payment structure, prevented them from practicing their primary care craft, preserving their professional and personal integrity, and providing optimal care. They developed business models that addressed the external environment (Figure 1, slice 3), which enabled them to mitigate the negative influences of fee for documentation, pressure for increased patient volume, and pay for performance based on externally determined metrics and evidence. Instead, they implemented models that allowed them to spend more time with patients, as well as to pay clinicians by salary or contract, not created on work-related value unit-based (wRVU) productivity.

While innovators chose different business models and visions of an optimal practice environment, they all created greater capacity for the external environment to support their internal motivations (Figure 1, slice 1) and their capacity to change (Figure 1, slice 2). (See Supplemental Table 1, available at http://www. AnnFamMed.org/content/17/3/250/supp1/DC1/.) We briefly highlight each practice's original motivations for change, identify components of their business model, and feature some internal transformations their models made possible. (Supplemental Table 2, available at http://www.AnnFamMed.org/content/17/3/250/ suppl/DC1/.)

\section{Practice 1: Encouraging Clinician Autonomy}

According to Practice 1's lead physician, Practice 1 was born of a desire to provide concierge-level care to a diverse population. The physician described herself as "burned out" after 3 years of practicing in a community health clinic and frustrated by conventional approaches to improving fee for documentation, which motivated her to find alternative ways to provide higher quality care while preventing burnout. "We can come up with any number of insurance schemes, and any number of quality improvement initiatives, and any number of value-based payment add-ons to the fee-for-service system, and none of it is going to make a difference," she said. Practice 1's solution was to offer direct primary care, where individuals paid a monthly membership fee, tiered by age, for $24 / 7$ access to specified primary care services via Internet, phone, or office visits. Practice 1 was initially backed by venture capital and within a few years had begun contracting with corporate clients while expanding to 6 different sites. (Supplemental Appendix 3, available at http://www. AnnFamMed.org/content/17/3/250/suppl/DC1/.)

Without insurance constraints, clinicians had more autonomy in caring for patients. Appointments were scheduled in 30-minute increments, and clinicians could schedule administrative time for care coordination activities (eg, seeking resources, following up on referrals, etc). "We don't let people fall through the cracks," one physician said. "A lot of what we do is on the computer and through the phone because you can do health care that way, but you can't get reimbursed for it [in fee for documentation]." Another physician commented, "In a fee-for-service world, it's all about office visits, office visits, office visits. We don't have that... So, for us, it's really about what the patient wants and what suits their lifestyle and is clinically appropriate." A third physician expressed enjoyment of this part of his job: "Patients really appreciate hearing directly from the provider, and I feel better about the care I provide."

\section{Practice 2: Creating Value by Building Relationships}

Practice 2 was one site of a nationwide health care organization cofounded by an academic internist whose desire to provide humanistic care led to the realization, according to 1 staff member, "We can't function in a fee-for-service world." Backed by venture capital, Practice 2 partnered (and shared risk) with a private insurer to service Medicare Advantage patients. Other sites within the larger organization contracted with different entities (eg, companies and other insurers). The insurer paid Practice 2 upfront and allowed freedom to decide how to spend that money. "Typically, in medicine, insurance is the enemy, 
and here they're our partner," said one physician. "In truth, a lot of our goals and objectives are aligned." The senior operations manager elaborated: "I guess the really high-level view for me is we're paid differently. It allows us to act differently and structure our day differently and care about different things. And those things really are the things that are of value to patients and to us." (Supplemental Appendix 3.)

Freed from normal reimbursement constraints, Practice 2 piloted several innovative workforce roles that allowed patients to develop relationships with staff beyond the physician. A new defining relationship was between patients and health coaches ( 3 per physician), nonmedical personnel whose work encompassed case management, medical assistance, care coordination, medical scribing, and motivational interviewing. "I actually think that a lot of the magic is around health coaches," the senior operations manager said, "because health coaches are literally hired not based on some qualification or licensure, but around, can you listen to someone? And can you help them problem solve?" Longer appointment times (30 to 60 minutes), coupled with frequent health coaching visits, gave physicians the time and resources to treat patients' multiple comorbidities. As one health coach noted, "It's a different way of practicing medicine, but it's [also] a completely different way of being a patient."

\section{Practice 3: Preventing Disease Through Lifestyle Change}

Practice 3 was established by 2 family physicians who wanted to provide affordable, community-minded family medicine "with a holistic twist." They had completed an integrative medicine fellowship and wanted to treat patients with a systems-biology mindset based on lifestyle modification. Practice 3 never had investors rather, the physician-owners worked in urgent care until they had saved enough money to open their direct primary care practice. One physician called Practice 3 "the slow crockpot version" of direct primary care, as compared with the "find it, move fast, blow it up" approach of organizations backed by venture capital. Providing affordable care was a priority, and the physicians "reverse engineered" their price point (flat monthly membership fee for all patients, regardless of age, plus standardized copay for office visits) by asking themselves, "Living [here], how much money do we need to be happy? How many days a week do we want to work, and how many patients do we want to see?" Settling on an appropriate price point and panel size had been a process of trial and error, but Practice 3 had found its niche, according to one physician: "We're doing great as a business, we like what we're doing, and we're helping people." (Supplemental Appendix 3.)
Practice 3 offered longer appointment times (20 minutes), which the physicians saw as essential to forging relationships necessary to advocate lifestyle change. Practice 3 also employed a part-time nutritionist and health coach. Patient attrition, however, was a challenge. Reflecting on exit interviews with individuals ending their memberships, one physician remarked, "Our medical success undermines our business success."

Practice 3 addressed attrition by reimagining the role of the primary care clinic to offer services, as one physician said, for "well people, people who don't identify with the sick role." It became a place for community involvement through free monthly classes to support healthy lifestyles. Staff were committed to playing a positive role in the community, and Practice 3 donated profits from nutritional supplement sales to different local charities. "In our dream world," said one physician, "we would be [even more] deeply interfaced with the community... [because] if you think about it, what's the largest influence on someone's health? It's the people and things that are around them."

\section{FUTURE DIRECTIONS}

Primary care D\&I has generally focused on evaluating strategies for helping practices implement evidencebased care to achieve quality metrics and meet policy requirements-practice change from the outside-in. Unintended consequences for many practices seem to be disempowerment, limited success, and more burnout from burden, disruption, and moral distress.

The 3 illustrative cases reveal it is possible for some primary care practices to seize ownership of their care and prioritize their craft of family medicine. These practices began with their founders' realization that matching their practice to their values was impossible, given the conventional financing system and commercial EHRs designed to serve it. They came to this conclusion differently but took similar action by developing business models that circumvented the limitations of fee for documentation and pay for performance.

Although their clinical care and business models differed, all 3 practices succeeded in shifting the source and directional emphasis of change from outside-in to inside-out. These examples compelled us to reimagine our approach to the science of dissemination and implementation: from helping practices comply with externally sourced evidence and recommendations to empowering practices to discover and enact their own wisdom within a challenging environment. Based on these examples, we seek to remind practitioners, researchers, and policy makers that internal and external forces are dynamic and mutually constitutive. 
Knowledge production and everyday practice are intimately linked. Moreover, it matters where one starts.

From this viewpoint of inside-out D\&I, new questions emerge: What would it look like to start interventions from the inside-out, helping practices reflect on their vision and craft and providing them with skills to develop sensing tools and measures to innovate in their interactions with the external environment? What if we helped practices build capacity to develop innovative business models or manage up in their larger organizations? How would we facilitate practices doing that? How can we better engage practices and their patients in the development of new evidence? We believe such questions, spurred by the examples of the 3 pioneer practices, have potential to open a new frontier in the science of dissemination and implementation and inform better health policy. ${ }^{55}$

\section{To read or post commentaries in response to this article, see it} online at http://www.AnnFamMed.org/content/17/3/250.

Key words: primary health care; implementation science; physicians' offices; burnout; professional

Submitted March 30, 2018; submitted, revised, November 12, 2018; accepted December 18, 2018.

Funding support: This study was funded by National Cancer Institute grant R01 CA176545 awarded to Benjamin F. Crabtree, PhD.

Acknowledgments: We thank the clinicians and staff at these 3 practices for allowing us to visit, for sharing their insights, and for extending our thinking about primary care practice redesign by leading through example.

Supplemental Materials: Available at http://www.AnnFamMed. org/content/17/3/250/suppl/DC1/.

\section{References}

1. Centers for Medicare $\&$ Medicaid Services. Comprehensive primary care nitiative. https://innovation.cms.gov/initiatives/ComprehensivePrimary-Care-Initiative/. Published 2012. Accessed Jul 3, 2017.

2. Edwards ST, Bitton A, Hong J, Landon BE. Patient-centered medical home initiatives expanded in 2009-13: providers, patients, and payment incentives increased. Health Aff (Millwood). 2014;33(10): 1823-1831.

3. Annis Emeott A, Markovitz A, Mason MH, et al. Four-year evolution of a large, state-wide patient-centered medical home designation program in Michigan. Med Care. 2013;51(9):846-853.

4. American Academy of Family Physicians, American Academy of Pediatrics, American College of Physicians, American Osteopathic Association. Joint principles of the patient-centered medical home. http://www.aafp.org/dam/AAFP/documents/practice_management/ pcmh/initiatives/PCMHJoint.pdf. Published Mar 2007. Accessed Jan 23, 2017.

5. Martsolf GR, Kandrack R, Schneider EC, Friedberg MW. Categories of practice transformation in a statewide medical home pilot and their association with medical home recognition. J Gen Intern Med. 2015;30(6):817-823.
6. Cohen DJ, Balasubramanian BA, Gordon L, et al. A national evaluation of a dissemination and implementation initiative to enhance primary care practice capacity and improve cardiovascular disease care: the ESCALATES study protocol. Implement Sci. 2016;11(1):86.

7. Nilsen P. Making sense of implementation theories, models and frameworks. Implement Sci. 2015;10:53.

8. Rosenthal MB, Dudley RA. Pay-for-performance: will the latest payment trend improve care? JAMA. 2007;297(7):740-744.

9. Rosenthal MB, Fernandopulle R, Song HR, Landon B. Paying for quality: providers' incentives for quality improvement. Health Aff (Millwood). 2004;23(2):127-141

10. Cronholm PF, Shea JA, Werner RM, et al. The patient centered medical home: mental models and practice culture driving the transformation process. J Gen Intern Med. 2013;28(9):1195-1201.

11. Leasure $E L$, Jones RR, Meade LB, et al. There is no "i" in teamwork in the patient-centered medical home: defining teamwork competencies for academic practice. Acad Med. 2013;88(5):585-592.

12. Tuepker A, Kansagara D, Skaperdas E, et al. "We've not gotten even close to what we want to do": a qualitative study of early patient-centered medical home implementation. J Gen Intern Med. 2014;29(Suppl 2):S614-S622.

13. Lanham HJ, McDaniel RR Jr, Crabtree BF, et al. How improving practice relationships among clinicians and nonclinicians can improve quality in primary care. Jt Comm J Qual Patient Saf. 2009;35(9):457-466.

14. Wise CG, Alexander JA, Green LA, Cohen GR, Koster CR. Journey toward a patient-centered medical home: readiness for change in primary care practices. Milbank Q. 2011;89(3):399-424.

15. Balasubramanian BA, Chase SM, Nutting PA, et al; ULTRA Study Team. Using Learning Teams for Reflective Adaptation (ULTRA): insights from a team-based change management strategy in primary care. Ann Fam Med. 2010;8(5):425-432.

16. Howard J, Shaw EK, Clark E, Crabtree BF. Up close and (inter) personal: insights from a primary care practice's efforts to improve office relationships over time, 2003-2009. Qual Manag Health Care. 2011;20(1):49-61.

17. Kieber-Emmons AM, Miller WLL. The patient-centered medical home $(\mathrm{PCMH})$ : framing typology for understanding the structure, function, and outcomes of PCMHs. J Am Board Fam Med. 2017;30(4):472-479.

18. Basu S, Phillips RS, Song Z, Landon BE, Bitton A. Effects of new funding models for patient-centered medical homes on primary care practice finances and services: results of a microsimulation model. Ann Fam Med. 2016;14(5):404-414

19. Magill MK, Ehrenberger D, Scammon DL, et al. The cost of sustaining a patient-centered medical home: experience from 2 states. Ann Fam Med. 2015;13(5):429-435.

20. Cohen DJ, Dorr DA, Knierim K, et al. Primary care practices' abilities and challenges in using electronic health record data for quality improvement. Health Aff (Millwood). 2018;37(4):635-643.

21. Puffer JC, Knight HC, O'Neill TR, et al. Prevalence of burnout in board certified family physicians. J Am Board Fam Med. 2017;30(2): 125-126.

22. Simonetti JA, Sylling PW, Nelson K, et al. Patient-Centered medical home implementation and burnout among VA primary care employees. J Ambul Care Manage. 2017;40(2):158-166.

23. Peterson LE, Baxley E, Jaén CR, Phillips RL. Fewer family physicians are in solo practices. J Am Board Fam Med. 2015;28(1):11-12.

24. Pink DH. Drive: The Surprising Truth About What Motivates Us. New York, NY: Penguin; 2011.

25. Braithwaite J, Marks D, Taylor N. Harnessing implementation science to improve care quality and patient safety: a systematic review of targeted literature. Int J Qual Health Care. 2014;26(3):321-329.

26. Rapport F, Clay-Williams R, Churruca K, Shih P, Hogden A, Braithwaite $J$. The struggle of translating science into action: Foundational concepts of implementation science. J Eval Clin Pract. 2018;24(1):117-126. 
27. Burns D. How change happens: the implications of complexity and systems thinking for action research. In: Bradbury H, ed. The Sage Handbook of Action Research. Thousand Oaks, CA: Sage Publications; 2015:434-445.

28. Leykum LK, Lanham HJ, Pugh JA, et al. Manifestations and implications of uncertainty for improving healthcare systems: an analysis of observational and interventional studies grounded in complexity science. Implement Sci. 2014;9:165.

29. Miller WL, Crabtree BF, Nutting PA, Stange KC, Jaen CR. Primary care practice development: a relationship-centered approach. Ann Fam Med. 2010;8 Suppl 1:S68-79; S92.

30. Tremblay MC, Martin DH, Macaulay AC, Pluye P. Can we build on social movement theories to develop and improve communitybased participatory research? a framework synthesis review. Am J Community Psychol. 2017;59(3-4):333-362.

31. Darroch F, Giles A. Decolonizing health research: Community-based participatory research and postcolonial feminist theory. The Canadian Journal of Action Research. 2014;15(3):22-36.

32. Miller WL, Crabtree BF, McDaniel R, Stange KC. Understanding change in primary care practice using complexity theory. J Fam Pract. 1998;46(5):369-376.

33. Miller WL, McDaniel RR Jr, Crabtree BF, Stange KC. Practice jazz: understanding variation in family practices using complexity science. J Fam Pract. 2001;50(10):872-878.

34. Stroebel CK, McDaniel RR Jr, Crabtree BF, Miller WL, Nutting PA, Stange KC. How complexity science can inform a reflective process for improvement in primary care practices. Jt Comm J Qual Patient Saf. 2005;31(8):438-446.

35. Braithwaite J, Churruca K, Ellis L. Complexity Science in HealthcareAspirations, Approaches, Applications and Accomplishments: A White Paper. North Ryde NSW, Australia: Australian Institute of Health Innovation; 2017.

36. Blumer H. Symbolic Interactionism, Perseptive and Method. Englewood Cliffs, NJ: Prentice Hall, Inc; 1969.

37. Peralta KJ. Toward a deeper appreciation of participatory epistemology in community-based participatory research. PRISM: A Journal of Regional Engagement. 2017;6(1):4.

38. Fals Borda O. Knowledge and People's Power: Lessons With Peasants in Nicaragua, Mexico and Colombia. New Delhi, India: Indian Social Institute; 1988.

39. Greenhalgh $T$, Jackson $C$, Shaw $S$, Janamian T. Achieving research impact through co-creation in community-based health services: literature review and case study. Milbank Q. 2016;94(2):392-429.

40. Jull J, Giles A, Graham ID. Community-based participatory research and integrated knowledge translation: advancing the co-creation of knowledge. Implement Sci. 2017;12(1):150.
41. Rubinstein EB, Miller WL, Hudson SV, et al. Cancer survivorship care in advanced primary care practices: a qualitative study of challenges and opportunities. JAMA Intern Med. 2017;177(12): 1726-1732.

42. Crabtree BF, Nutting PA, Miller WL, et al. Primary care practice transformation is hard work: insights from a 15-year developmental program of research. Med Care. 2011;49(Suppl):S28-S35.

43. Nutting PA, Crabtree BF, Miller WL, Stange KC, Stewart E, Jaén C. Transforming physician practices to patient-centered medical homes: lessons from the national demonstration project. Health Aff (Millwood). 2011;30(3):439-445.

44. Cohen DJ, Crabtree BF, Etz RS, et al. Fidelity versus flexibility: translating evidence-based research into practice. Am J Prev Med. 2008; 35(5)(Suppl):S381-S389.

45. Stange KC, Zyzanski SJ, Jaén CR, et al. Illuminating the 'black box'. A description of 4454 patient visits to 138 family physicians. J Fam Pract. 1998;46(5):377-389.

46. Crabtree BF, Miller WL, Tallia AF, et al. Delivery of clinical preventive services in family medicine offices. Ann Fam Med. 2005;3(5): 430-435.

47. Goodwin MA, Zyzanski SJ, Zronek S, et al.; The Study to Enhance Prevention by Understanding Practice (STEP-UP): a clinical trial of tailored office systems for preventive service delivery. Am J Prev Med. 2001;21(1):20-28.

48. Cohen D, McDaniel RR Jr, Crabtree BF, et al. A practice change model for quality improvement in primary care practice. J Healthc Manag. 2004;49(3):155-168, discussion 169-170.

49. Donahue KE, Newton WP, Lefebvre A, Plescia M. Natural history of practice transformation: development and initial testing of an outcomes-based model. Ann Fam Med. 2013;11(3):212-219.

50. Chambers DA, Glasgow RE, Stange KC. The dynamic sustainability framework: addressing the paradox of sustainment amid ongoing change. Implement Sci. 2013;8:117.

51. McGinnis JM, Stuckhardt L, Saunders R, Smith M. Best Care at Lower Cost: The Path to Continuously Learning Health Care in America. Washington, DC: National Academies Press; 2013.

52. Magretta J. Why business models matter. Harv Bus Rev. 2002;80(5): 86-92,133.

53. Morris $M$, Schindehutte $M$, Allen J. The entrepreneur's business model: toward a unified perspective. J Bus Res. 2005;58(6):726-735.

54. Cohen DJ, Crabtree BF. Evaluative criteria for qualitative research in health care: controversies and recommendations. Ann Fam Med. 2008;6(4):331-339.

55. Park B, Gold SB, Bazemore A, Liaw W. How evolving United States payment models influence primary care and its impact on the quadruple aim. J Am Board Fam Med. 2018;31(4):588-604. 